\title{
Urinary tract infection in women
}

\section{Krzysztof Czajkowski ${ }^{1}$, Magdalena Broś-Konopielko', Justyna Teliga-Czajkowska²}

III Faculty and Clinic of Obstetrics and Gynaecology, Medical University of Warsaw, Warsaw, Poland

${ }^{2}$ Department of Obstetrics and Gynaecology Didactics, Faculty of Health Sciences, Medical University of Warsaw, Warsaw, Poland

\begin{abstract}
Urinary tract infection (UTI) is one of the most common infections afflicting women. UTI often accompanies vaginal infections and is frequently caused by pathogens originating in the digestive tract. The paper discusses the prevalence of UTI in various patient populations, including postmenopausal, pregnant, diabetic, epileptic, and perioperative female patients. Current UTI treatment and prevention guidelines both for primary and recurring UTIs were reviewed. Antibiotic treatment duration should be minimized, with the exact dosage and time schedule depending on the type of infection. Asymptomatic bacteriuria does not always require antibiotic treatment, because their excessive use may lead to the emergence of antibiotic resistant strains. The role of nonantibiotic prophylaxis of recurrent infections involving immunomodulants (OM-89), probiotics, and behavioural interventions was underlined.
\end{abstract}

Key words: urinary tract infections, menopause, pregnancy, prevention, treatment.

\section{Introduction}

Urinary tract infections (UTIS) in women are one of the most prevalent infections occurring at various stages of life. Women are much more prone to UTIs than men, mainly due to the female lower urinary tract anatomy and its proximity to the reproductive organs. The female urethra is relatively short, reducing the distance for bacterial ingress. Furthermore, it opens into the vulvar vestibule, i.e. a structure that is also quite prone to infections, given the prevalence of vulvar vestibulitis and vaginitis. In this case, sexual activity as well excessive use of intimate hygiene products interfering with natural vaginal microbiome are often to blame. On the other hand, the proximity of the anus facilitates the colonization of both the reproductive organs and distal parts of the urinary tract by Escherichia coli, Enterococcus fecalis, and the Streptococcus species. Pregnancy and the perinatal period are other characteristic timepoints marked by frequent urinary tract infections. The increasing number of caesarean sections and perioperative catheterizations are yet another risk factor. In the post-menopausal period falling oestrogen levels interfere with the vaginal epithelium, contributing to its gradual atrophy, while glycogen deficiency reduces the lactic acid bacteria counts. As a result, post-menopausal vaginas are often colonized by other bacteria, mainly Escherichia coli, which may spread and infect the urinary tract. Pelvic organ prolapse and urinary in- continence also contribute to frequent UTIs. These are believed to affect between $30 \%$ and $50 \%$ of women above the age of 50 years. It is estimated that every other woman will have had at least one UTI during her lifetime [1, 2], with $10-60 \%$ of all women having a symptomatic UTI at least once in their lives $[3,4]$. The infection risk increases with age [5].

Recurring UTIs in women are defined as at least 2 UTIs occurring within a 6-month period or at least 3 UTIs in a 12-month period. The prevalence of recurring UTIs in women is estimated at $25-50 \%$ of all infections [6-9].

\section{Diagnosis}

All UTI cases can be classified as either asymptomatic or symptomatic. An asymptomatic UTI is diagnosed based on urinalysis results. Careful sample collection is crucial given the external urethral opening position in women. The number of leukocytes is the key criterion utilized in UTI diagnosis; a count > 10 leukocytes $/ \mathrm{mm}^{3}$ suggests an infection. In pregnant patients the cut-off is higher, at $>20$ leukocytes $/ \mathrm{mm}^{3}$. Sample contamination by vaginal secretions containing mucus and lactic acid bacteria may result in erroneous diagnosis of multiple mucus threads and abundant bacterial growth in urine sediment. Sometimes the mucus even 
yields a mistaken diagnosis of proteinuria. Period, postpartum bleeding, or any other uterine bleeding may result in sample contamination with red blood cells. In such cases, a detailed history and a better-prepared repeat analysis is necessary. Urinalysis results not accompanied by the patient's symptoms are not sufficient to initiate treatment. A urine culture can be used to confirm or disprove a hypothesis of an UTI. The culture sample should be collected in a sterile container to avoid contamination, preferably from first morning urine. The presence of $\geq 10^{5}$ colony forming units per millilitre $(\mathrm{CFU} / \mathrm{mL})$ confirms an infection, while an antibiogram will help verify the efficacy of a given treatment.

In the case of elevated leukocyte values in urine sediment combined with clinical symptoms, treatment should be initiated. When dealing with pregnant patients, it is recommended to take a culture sample at the start of treatment due to increased risk of premature birth associated with urinary tract infections as well as limited antibiotic treatment options compatible with pregnancy. Typical symptoms will still indicate the need for treatment. In the absence of abnormal vaginal discharge and burning sensation in the vulvar vestibule, typical UTI symptoms lead to infection confirmation in as many as $90 \%$ of young women $[10,11]$. In $15 \%$ of cases, urine cultures are positive in spite of elevated leukocyte count in the urinalysis [3].

\section{Characteristic patient groups}

The main reasons behind the increased prevalence of urinary tract infections in peri- and postmenopausal women include hormonal changes (oestrogen insufficiency) and connective tissue aging (urinary incontinence, pelvic organ prolapse). Factors conducive to UTIs in the perimenopausal period include urinary incontinence (impeding proper hygiene), atrophy of vaginal mucous membranes (increasing the risk of vaginal infections that may spread into the urinary tract), and anterior vaginal prolapse (precluding complete voiding of the bladder). Prevalence of asymptomatic bacteriuria increases in the peri- and postmenopausal period, reaching levels of $4-19 \%$ as compared to $1.5 \%$ in premenopausal women [12]. In peri- and postmenopausal women, oestrogen deficiency may be conducive to both urinary incontinence and urinary tract infections. Topical vaginal (but not systemic) application of oestrogens was proven to significantly reduce the risk of bacteriuria $(\mathrm{OR}=0.3 ; 95 \% \mathrm{Cl}: 0.13-0.68)$ [13]. The recommendation of topical oestrogen use in peri- and postmenopausal patients to prevent UTIs is also included in guidelines published by research associations [14].

Diabetes constitutes a significant UTI risk factor for postmenopausal women $[15,16]$. Studies involving a total of 256,725 females with type 2 diabetes showed sig- nificantly more prevalent UTI diagnoses starting from ages 45-49 years onward, with the difference as high as $100 \%$ in the said age range and yet another $80 \%$ for those aged 50-54 years [16]. Another study compared 2 groups of women aged 55-75 years diagnosed with acute UTI - 901 diabetic patients and 913 controls [15]. Diabetes in postmenopausal women turned out to increase UTI risk twofold $(\mathrm{OR}=2.2 ; 95 \% \mathrm{Cl}$ : 1.5-3.1). Significant factors included oral pharmacotherapy or insulin treatment (OR 2.8 and 2.7, respectively) and type 2 diabetes $(O R=2.2)$. Disease duration and glycaemia control assessed by glycated haemoglobin $\mathrm{HbA1c}$ levels turned out not to be significant. In patients 57 years and older, undergoing surgical treatment constitutes yet another risk factor for UTIs [17].

Diabetes mellitus, uncontrolled in particular, is a risk factor for both urinary and reproductive tract infections (involving the vulva, vulvar vestibule, and/or vagina). Fourteen per cent of women with type 1 diabetes and $23 \%$ of women with type 2 diabetes are diagnosed with UTIs [18]. The most significant risk factors in this group include glycaemia control and glycosuria. Infections are also more prevalent in perimenopausal patients with longer disease duration. In a well-documented trial involving 1357 female patients with type 1 diabetes, increased prevalence was observed for the following: acute cystitis (OR $=1.46 ; 95 \% \mathrm{Cl}: 1.10-1.95 ; p=0.001)$, acute vaginitis (OR $=1.20 ; 95 \% \mathrm{Cl}: 1.01-1.42 ; p=0.044)$, and acute vulvitis (OR $=2.12 ; 95 \% \mathrm{Cl}: 1.56-2.90 ; p<0.001)$ [10]. In a group of 241 women with type 1 diabetes, the most significant risk factors for symptomatic infections included sexual intercourse, use of oral contraceptives, and microangiopathy [18]. Urinary incontinence, more prevalent in diabetic females than in the general population, may be another contributing factor $(\mathrm{OR}=1.64$; 95\% Cl: 1.19-2.26; $p=0.001$ ) [10]. In type 2 diabetes, asymptomatic bacteriuria is more frequent than in healthy controls $(17.5 \%$ vs. $10 \%, p=0.015)$. Asymptomatic bacteriuria may progress to symptomatic UTI in $20 \%$ of patients during 6 months $[19,20]$. In another study of 348 women with type 2 diabetes, asymptomatic bacteriuria also constituted the primary risk factor for developing a symptomatic infection [18]. It may also lead to decreased renal function [21]. The available data suggest that periodic urine cultures in diabetic patients, in particular those with type 2 diabetes, should be recommended.

Epileptic patients were also recognized as requiring more frequent UTI treatment than the general population [22], with the problem affecting around 58\% women and $42 \%$ diagnosed with epilepsy ( $p<0.0001)$. An analysis of reasons revealed that the most significant cause underlying the increased UTI prevalence in this population were anti-epileptic drugs. Urinary tract infections occurred more frequently in patients using phenytoin $(\mathrm{OR}=1.78 ; 95 \% \mathrm{Cl}: 1.24-2.55 ; p=0.001)$, 
primidone $(\mathrm{OR}=1.73 ; 95 \% \mathrm{Cl}: 1.21-2.49 ; p=0.002)$, carbamazepine (OR $=1.61 ; 95 \% \mathrm{Cl}: 1.33-1.96 ; p<0.0001)$, and valproate $(\mathrm{OR}=1.52 ; 95 \% \mathrm{Cl}: 1.28-1.82 ; p<0.0001)$, probably due to their immunomodulating properties. The said studies suggest the need to carefully plan therapies for epileptic patients with recurrent urinary tract infections.

Another group with elevated UTI risk are patients with indwelling urinary catheter or those requiring intermittent self-catheterization [23]. UTIs occur more than once a year in $15.4 \%$ to $86.6 \%$ patients in that group, with antiseptic product use probably reducing the risk.

The perioperative period may also be conducive to urinary tract infections [17]. Age above 57-60 years, diabetes, immunosuppressant therapy, obesity, and blood transfusions due to iatrogenic all constitute additional risk factors in this case. Preventative administration of antibiotics to patients catheterized for surgery with diagnosed asymptomatic bacteriuria significantly reduces the risk of progression to symptomatic infection $(R R=0.20 ; 95 \% \mathrm{Cl}: 0.13-0.31)$ [24]. Female patients are catheterized for a vast majority of surgeries due to their reproductive anatomy. In the case of caesarean sections, the catheter may stay in for a few hours after block anaesthesia, while with gynaecological procedures it typically stays in for around 24 hours. Surgical repairs of pelvic organ prolapse are an exception, however, requiring catheterization for 2-3 days at times.

Pregnancy is accompanied by a series of factors conducive to urinary tract infections - the urine is more basic in pregnant women, urine flow obstruction is more common (especially towards the end of pregnancy), as is proteinuria, diabetes, and anaemia. Taking a urinalysis sample is more difficult, in particular in the $3^{\text {rd }}$ trimester, resulting in protein and bacteria detected in the samples that do not always signify an infection - typically these result from sample contamination by vaginal secretions. Protein may originate from mucus contamination, but in hypertensive patients it suggests proteinuria characteristic of preeclampsia. Multiple bacteria in the field of view when analysing urine sediment are typically lactic acid bacteria if the reading is not accompanied by elevated leukocyte count, with the latter constituting a key factor for differential diagnosis against UTI in a pregnant patient. Asymptomatic urinary tract infections affect $2-8 \%$ of pregnant women [25]. According to other sources, UTIs constitute the most common infections of pregnancy, diagnosed in as many as $50-60 \%$ of all pregnant women [26]. Research results suggest an increased prevalence of preterm birth associated with asymptomatic bacteriuria [27]. UTI is diagnosed more frequently in women with gestation-induced hypertension, and as such it is linked to increased risk of intrauterine growth restriction, premature birth, and caesarean section [28]. It must be remembered, however, that a UTI diagnosis in itself does not necessitate any specific obstetric intervention. Recurrent urinary tract infections affect 1 in 4 pregnant women diagnosed with UTI and lead to pyelonephritis in $4-5 \%$ of cases [25]. UTI in a pregnant woman was also found to constitute a significant risk factor with regard to the child's UTI, at $30 \%$ vs. $6.8 \%(O R=5.9$ at 95\% Cl: 1.9-18.3; $p=0.001$ ) [29].

\section{Bacteria identification key to therapy selection}

Studies analysing the typology of pathogens causing urinary tract infections in non-diabetic patients quote Escherichia coli (69\%), Enterococcus sp. (10\%), Klebsiella sp. (4\%), Pseudomonas aeruginosa (4\%), Proteus sp. (4\%), and Staphylococcus sp. (2\%) as the most prevalent bacteria [30, 31]. For diabetic patients, the most typical pathogens observed were Escherichia coli (71\%), Klebsiella spp (6\%), Staphylococcus spp (5\%), and Enterococcus spp (4\%) [31]. In pregnant women, urinary tract infections are usually caused by Escherichia coli (30.8-90\%), bacteria from the Staphylococcus genus (4.3-32\%), Proteus mirabilis (10.2\%), Enterococcus faecalis (1-8.1\%), and Klebsiella pneumoniae (6.1-9.1\%) $[25,26,32]$. In infants, the most common pathogens included Escherichia coli (65.9\%), Klebsiella (14.6\%), and Staphylococci (9.8\%) [29].

\section{Antibiotic treatment}

French guidelines issued by the French Language Infectious Pathology Society recommend sequential administration of fosfomycin, nitrofurantoin, and quinolones to treat cystitis, and third-generation cephalosporins to treat pyelonephritis [33].

Antibiotic dosages proposed by international associations are included in the Table 1 [14].

Any treatment of pregnant patients with asymptomatic bacteriuria should be targeted, requiring a urine culture antibiogram prior to treatment initiation. In acute cases treatment should be initiated while waiting for culture results. Cephalosporins are the drug of choice in pregnant patients. Kashif et al. [25] suggest particular caution when treating pregnant women with nitrofurantoin (because it may cause haemolytic disease of the foetus), augmentin (necrotizing enterocolitis was observed in foetuses in the 3rd trimester), and trimethoprim (folic acid antagonist). Between 7 and 10 days after treatment course completion a repeat urine culture should be taken to confirm treatment efficacy. Single-dose fosfomycin can be a good treatment alternative. A meta-analysis published in 2020 showed its efficacy to match that of other antibiotics while 
Table 1. Proposed antibiotic dosage (based on guidelines published by the American Urological Association, Canadian Urological Association, Society of Urodynamics, Female Pelvic Medicine \& Urogenital Reconstruction, and the European Urological Society)

\begin{tabular}{|c|c|c|c|}
\hline Indication & Antibiotic & Dosage & Treatment duration \\
\hline \multirow{5}{*}{$\begin{array}{l}\text { Prophylaxis in asymptomatic } \\
\text { bacteriuria; continuous } \\
\text { treatment }\end{array}$} & Trimethoprim & $100 \mathrm{mg} 1 \times$ a day & \\
\hline & Trimethoprim + sulfamethoxazole & $\begin{array}{l}\text { 40-200 mg } 1 \times \text { a day } \\
40-200 \mathrm{mg} 3 \times \text { a week }\end{array}$ & \\
\hline & Nitrofurantoin & 50-100 mg a day & \\
\hline & Cephalexin & $125-250 \mathrm{mg} 1 \mathrm{x}$ a day & \\
\hline & Fosfomycin & 3 g every 10 days & \\
\hline \multirow[t]{3}{*}{$\begin{array}{l}\text { Prophylaxis in asymptomatic } \\
\text { bacteriuria; periodic treatment }\end{array}$} & Trimethoprim + sulfamethoxazole & $\begin{array}{l}40 / 200 \mathrm{mg} \\
80 / 400 \mathrm{mg}\end{array}$ & \\
\hline & Nitrofurantoin & $50-100 \mathrm{mg}$ & \\
\hline & Cephalexin & $250 \mathrm{mg}$ & \\
\hline \multirow[t]{7}{*}{ Uncomplicated cystitis } & Fosfomycin & $3 g$ & For 1 day \\
\hline & Nitrofurantoin & 50-100 mg a day & For 5 days \\
\hline & Extended-release nitrofurantoin & 100 mg $2 \times$ a day & For 5 days \\
\hline & Pivampicillin & 400 mg $3 \times$ a day & For 3-5 days \\
\hline & Cephalosporins & 500 mg $2 \times$ a day & For 3 days \\
\hline & Trimethoprim + sulfamethoxazole & $80 / 400 \mathrm{mg} 2 \times$ a day & For 3 days \\
\hline & Trimethoprim & $100 \mathrm{mg} 2 \times$ a day & For 3-5 days \\
\hline \multirow[t]{5}{*}{ Complicated cystitis } & Ciprofloxacin & 500-750 mg 2× a day & For 7 days \\
\hline & Levofloxacin & 750 mg a day & For 5 days \\
\hline & Trimethoprim + sulfamethoxazole & $160 / 800 \mathrm{mg} 2 \times$ a day & For 14 days \\
\hline & Cefpodoxime & $200 \mathrm{mg} 2 \times$ a day & For 10 days \\
\hline & Ceftibuten & 400 mg a day & For 10 days \\
\hline \multirow{4}{*}{$\begin{array}{l}\text { Pyelonephritis, parenteral } \\
\text { therapy } \\
1^{\text {st }} \text { line of treatment }\end{array}$} & Ciprofloxacin & 400 mg $2 \times$ a day & \\
\hline & Levofloxacin & 750 mg a day & \\
\hline & Cefotaxime & 2 g $3 x$ a day & \\
\hline & Ceftriaxone & 1-2 g a day & \\
\hline \multirow{4}{*}{$\begin{array}{l}\text { Pyelonephritis, parenteral } \\
\text { therapy } \\
2^{\text {nd }} \text { line of treatment }\end{array}$} & Cefepime & $1-2$ g $2 \times$ a day & \\
\hline & Piperacillin/tazobactam & $2.5-4.5$ g $3 \times$ a day & \\
\hline & Gentamycin & $5 \mathrm{mg} / \mathrm{kg}$ a day & \\
\hline & Amikacin & 15 mg/kg a day & \\
\hline
\end{tabular}

Not all antibiotics are available in Poland.

maintaining high safety levels both in pregnant and non-pregnant patients [34].

Studies by Malmartel et al. [31] analysed the prevalence of antibiotic-resistant bacteria causing urinary tract infections. Resistance to ofloxacin and cefixime was slightly higher in diabetic patients, see data in Table 2.

\section{Non-antibiotic prophylactic treatment - immunomodulation}

OM-89 is an immunomodulatory drug $[11,36]$. It is effective against Escherichia coli infections, constituting $70-80 \%$ of all urinary tract infections. Women with recurring urinary tract infections treated with OM-89 for 6 months had a twofold reduced further recurrence rate (67.3\% vs. $32.7 \%)$ [37]. Uncontrolled diabetes significantly reduced the treatment efficacy, however. In
Table 2. Percentage of strains resistant to selected antibiotics

\begin{tabular}{lcc}
\hline Antibiotic & \multicolumn{2}{c}{ Percentage of resistant strains } \\
\cline { 2 - 3 } & $\begin{array}{c}\text { In study by } \\
\text { Malmartel [31] }\end{array}$ & $\begin{array}{c}\text { According to } \\
\text { NICE guidelines [23] }\end{array}$ \\
\hline Ofloxacin & $10.8 \%$ & \\
\hline Cefixime & $3.8 \%$ & $9.9 \%$ \\
\hline $\begin{array}{l}\text { Trimethoprim, } \\
\text { sulfamethoxazole }\end{array}$ & $16.8 \%$ & $30.3 \%$ \\
\hline Nitrofurantoin & $4.05 \%$ & $2.5 \%$ \\
\hline Fosfomycin & $3.2 \%$ & \\
\hline Pivampicillin & & $7.5 \%$ \\
\hline
\end{tabular}

NICE - National Institute for Health and Care Excellence

a multi-centre double blind study involving 453 women, a $34 \%$ reduction of urinary tract infections was observed after 3 months of initial treatment and a 10-day booster course of OM-89 [30]. The same treatment structure 
was utilized in a retrospective study of 79 patients, with Escherichia coli identified as the main pathogen in 49\% of the population [11]. Sixty-three per cent of those infected with Escherichia coli and 53\% of the whole population had a positive response to treatment.

OM-89 efficacy was also confirmed in a study involving menopausal women. A clinical trial was carried out with a group of patients aged 66 years on average. The number of recurrent infections in the group dropped from 3.4 to 1.8 (a reduction of $65 \%$ ) after the immunomodulatory treatment [38].

OM-89 oral immunomodulatory treatment for the prevention of recurring UTIs is recommended both by the European Association of Urology (EAU) in uncomplicated UTIs in women (strong evidence, highest recommendation level, 1a) [12] and by the Polish Association of Urology in prevention of recurring urinary tract infections. The treatment helps reduce the frequency of recurring infections, patients' symptoms, antibiotic prescriptions, and the risk of antibiotic resistance [39]. To prevent recurring UTIs, OM-89 is administered once a day before a meal, for a total of 90 days. The drug can be used in parallel with antibiotic treatment during the acute phase of an infection, without prior urine culture results, because it induces a strong immune response not only to $E$. coli, but also to other pathogens causing UTIs.

OM-89 is characterized by the highest level of evidence of all non-antibiotic methods of UTI prevention [12].

\section{Other non-antibiotic methods of prevention}

In accordance with the 2017 Cochrane database analysis [40], the impact of probiotics on reducing urinary tract infections in patients with bladder function disorders requires further research.

In vitro studies have shown that cranberry juice reduces adherence of Escherichia coli bacteria to the urinary tract and vaginal epithelium [41, 42]. As a result, patients' symptoms associated with bacterial irritation should be relieved. Reduced symptom levels, however, are not equivalent to infection eradication. Prospective randomized trials with women aged 18-45 years did not detect any statistically significant difference in UTI prevalence diagnosed by urine cultures between groups drinking cranberry juice and those drinking placebo [43]. Similar conclusions were presented in a Cochrane analysis published in 2012 [44].

Treatment of chronic urinary tract infections and preventing further recurrences is yet another challenge. D-mannose was found to be efficient in preventing recurring UTIs by reducing bacterial adherence to urinary tract epithelium. A meta-analysis published in 2020 included 8 papers overall, but the final results were based on data from merely 163 patients [35]. The results are promising, but further research is necessary to determine the optimum dosage and treatment duration.

\section{Antibiotic prophylaxis}

Some doctors recommend long-term prophylactic use of antibiotics in women with recurring urinary tract infections. A Cochrane meta-analysis indicated positive outcomes of prophylactic use of antibiotics in young women with recurring UTIs [45]. Results published by Ahmed et al. [46], however, show that long-term antibiotic prophylaxis had positive outcomes in patients aged 65 years and above only when continued for more than 2 years. The patients received nitrofurantoin, cephalexin, or trimethoprim. The treatment reduced the frequency of recurring symptomatic urinary tract infections $(\mathrm{OR}=0.57 ; 95 \% \mathrm{Cl}: 0.55-0.59)$ and the need for additional antibiotic prescriptions $(\mathrm{OR}=0.61 ; 95 \% \mathrm{Cl}$ : 0.59-0.62). At the same time, a small but statistically significant increase of hospitalizations due to UTIs was observed (OR $=1.16 ; 95 \% \mathrm{Cl}: 1.05-1.28)$.

According to EAU guidelines, antibiotic prophylaxis should be introduced when neither behavioural interventions nor non-antibiotic prevention is successful.

\section{International and domestic recommendations}

According to American Urological Association (AUA), Canadian Urological Association (CUA), and Society of Urodynamics (SUFU), Female Pelvic Medicine, and Urogenital Reconstruction guidelines, most recommendations are classified as level B or C [14]. Diagnosis of recurring UTI should always be confirmed by a urine culture. Prior to treatment initiation, the practitioner should review urinalysis and urine culture results. In case of very severe symptoms, however, antibiotic treatment may be initiated while waiting for laboratory test results. Asymptomatic bacteriuria should not be treated; it does not necessitate urinalyses or urine cultures, either. Antibiotic treatment of symptomatic UTI (with nitrofurantoin, trimethoprim-sulfamethoxazole, and fosfomycin as the first line of treatment) should follow the results of an antibiogram. Antibiotic treatment should not exceed 7 days, and it may be administered parenterally whenever required. If symptoms recede, no post-treatment laboratory tests are required. If symptoms persist, a repeat urine culture should be carried out to guide further treatment. Topical vaginal administration of oestrogens is recommended in post- and perimenopausal women (unless there are contraindications). In accordance with the WHO plan to counteract inducing excessive antibiotic resistance, the aforementioned research associations permit prophylactic use of cranberry and other alternative therapies. 
European Association of Urology guidelines are complete with a note providing a current literature review [12]. The strength levels of the recommendations were also provided. The authors recommend not diagnosing or treating asymptomatic bacteriuria with the exception of pregnant patients (weak recommendation) and patients with discontinuity of mucous membranes of the bladder (strong recommendation). When considering an uncomplicated urinary tract infection, the diagnosis should be based on clinical symptoms in the absence of vaginal infection. Urinary culture is recommended only when considering a diagnosis of acute pyelonephritis, dealing with pregnant patients, and women with unconventional presentation of symptoms or symptoms not receding within four weeks after treatment completion. The first line of treatment should include fosfomycin, pivampicillin, or nitrofurantoin. Treatment of uncomplicated cystitis with aminopenicillins or fluoroquinolones is not recommended (strong recommendation). The authors indicated that using test strips to diagnose uncomplicated cystitis carried low strength of evidence. Diagnosis of recurring UTI must be confirmed by urine culture with antibiogram. Non-antibiotic prevention of recurring infections should involve, as the first line of treatment, behavioural interventions and OM-89 immune system stimulation.

Antibiotic prophylaxis is only recommended in the case of UTI recurring in spite of non-antibiotic prevention - antibacterial prophylaxis after sexual intercourse, periodic short-term antibacterial treatment in women for whom the treatment was successful (strong recommendation). At the same time, the recommendation to treat postmenopausal women with oestrogens and introduce behavioural modifications, and the wide use of imaging technologies in women with uncomplicated cystitis was classified as weak in terms of evidence. Urinalysis (laboratory based or strip test), urine culture, and imaging are recommended in all cases of pyelonephritis. The authors of the guidelines recommend treatment of uncomplicated pyelonephritis with short courses of fluoroquinolones and hospitalization only in the case of parenteral antibiotic administration, until the patient can be converted to an oral route. At the same time, treatment with nitrofurantoin, fosfomycin, or pivampicillin is not recommended (strong recommendation). In the case of complicated recurring pyelonephritis, aminoglycosides combined with amoxicillin or second-generation cephalosporin is recommended. Another option is intravenous treatment with third-generation cephalosporin in the case of generalized symptoms emerging. Ciprofloxacin is only recommended for oral treatment of cases that do not require hospitalization, or for patients with known allergies to the other available antibiotics. Ciprofloxacin and other fluoroquinolones are contraindicated if the patient has received them in the past 6 months (strong recommen- dation). The authors do not recommend routine antibiotic treatment in patients after catheter removal.

The British committee National Institute for Health and Care Excellence guidelines published in 2020 discuss treatment of lower urinary tract infections [47]. Outside of pregnancy, a 3-day treatment course is as effective as 5-day or 10-day courses. In older women, the treatment may continue for 3 to 6 days. Nitrofurantoin or trimethoprim is the recommended first-line treatment, with fosfomycin or pivampicillin constituting the second line of treatment. Pregnant patients should be treated for 7 days, making sure that, prior to treatment initiation, no antibiotic resistance to the selected drug has been observed in the past. Drugs recommended in cases of asymptomatic bacteriuria include nitrofurantoin, amoxicillin, and cefalexin, and in the case of symptomatic infections - amoxicillin or cefalexin.

Polish guidelines for the diagnosis, treatment and prevention of urinary tract infections in adults were developed in 2015 under the National Antibiotic Protection Program [48]. Asymptomatic bacteriuria requires treatment with antibiotics only during and before surgery of the urinary system. Treatment of acute uncomplicated cystitis in young women can be undertaken based on clinical symptoms. In such cases the diagnosis does not require laboratory test results, such as urine sediment test or urine culture. Most patients may receive outpatient treatment. According to the guidelines, evidence-based treatment of uncomplicated cystitis should not involve fluoroquinolones. These should be limited to treatment of complicated or severe cases. In the case of recurrence, a urine culture should be taken together with evidence-based antibiotic treatment initiated while waiting for laboratory test results. In the case of complicated UTIs, the following tests should be carried out: urinalysis, blood panel, CRP, creatinine concentration, GRF, and urine culture. Treatment should be modified in line with antibiogram results. Acute pyelonephritis diagnosed based on clinical presentation should always be confirmed by a urine culture, accompanied by a blood culture for more severe cases. Initial evidence-based treatment should be modified to account for culture results. For pregnant patients, the authors recommend a urine culture in the first trimester of pregnancy, to prevent pyelonephritis and premature birth risk. In the case of cystitis in the patient's history, repeat urine cultures should be taken every 1-2 months. Fluoroquinolones are contraindicated throughout the pregnancy, and co-trimoxazole should not be used in the first trimester.

\section{Conclusions}

Urinary tract infection is one of the most common infections afflicting women. UTI occurs in females at any age, with the highest prevalence in pregnant and 
postmenopausal patients. UTI often accompanies vaginal infections and is frequently caused by pathogens originating in the final section of the digestive tract. Antibiotic treatment duration should be minimized, with the exact dosage and time schedule depending on the type of infection.

Asymptomatic bacteriuria does not always require antibiotic treatment, because their excessive use may lead to the emergence of antibiotic resistant strains. When dealing with chronic infections and asymptomatic bacteriuria, alternative treatment to reduce the risk of recurrence should always be considered.

For recurrent urinary tract infections, non-antibiotic prevention is recommended as the first line of treatment, based on behavioural interventions and immune system modulation.

\section{Disclosure}

The authors report no conflict of interest.

\section{References}

1. Fihn SD. Clinical practice. Acute uncomplicated urinary tract infection in women. N Engl J Med 2003; 349: 259-266.

2. Griebling TL. Urologic diseases in America project: trends in resource use for urinary tract infections in women. J Urol 2005; 173: 1281-1287.

3. Curtiss N, Meththananda I, Duckett J. Urinary tract infection in obstetrics and gynaecology. Obstet Ginecol Reprod Med 2017; 27: 261-265.

4. Foxman B. Urinary tract infection syndromes: occurrence, recurrence, bacteriology, risk factors, and disease burden. Infect Dis Clin North Am 2014; $28: 1$.

5. Ikäheimo R, Siitonen A, Heiskanen T, et al. Recurrence of urinary tract infection in a primary care setting: analysis of a 1-year follow-up of 179 women. Clin Infect Dis 1996; 22: 91-99.

6. Foxman B. Recurring urinary tract infection: incidence and risk factors. Am J Public Health 1990; 80: 331-333.

7. Geerlings SE. Clinical presentations and epidemiology of urinary tract infections. Microbiol Spectr 2016; 4.

8. Gupta K, Trautner BW. Diagnosis and management of recurrent urinary tract infections in nonpregnant women. BMJ 2013; 346: $\mathrm{f} 3140$.

9. Scholes D, Hooton TM, Roberts PL, et al. Risk factors for recurrent urinary tract infection in young women. J Infect Dis 2000; 182: 1177-1182.

10. Van den Boom L, Kalder Ms, Kostev K. Prevalence of urinary system, pelvic organ, and genital tract disorders among women with type 1 diabetes in Germany. Primary Care Diabetes 2021; 15: 257-261.

11. Brodie A, El-Taji O, Jour I, et al. A retrospective study of immunotherapy treatment with uro-vaxom $\left(\mathrm{OM}-89{ }^{\circledR}\right)$ for prophylaxis of recurrent urinary tract infections. Curr Urol 2020; 14: 130-134.

12. Bonkat $G$, Bartoletti R, Bruyère $F$, et al. EAU guidelines on urological infections European as sociation of Urology 2020.

13. Cody JD, Jacobs ML, Richardson K, Moehrer B, Hextall A. Oestrogen therapy for urinary incontinence in post-menopausal women. Cochrane Database Syst Rev 2012; 10: CD001405.

14. Anger J, Lee $U$, Ackerman AL, et al. Recurrent uncomplicated urinary tract infections in women: AUA/CUA/SUFU guideline. J Urol 2019; 202: 282289.

15. Boyko EJ, Fihn SD, Scholes D, et al. Diabetes and the risk of acute urinary tract infection among postmenopausal women. Diabetes Care 2002; 25: 1778-1783.

16. Wilke T, Boettger B, Berg B, et al. Epidemiology of urinary tractinfections intype2 diabetesmellitus patients: Ananalysis based on a large sample of 456,586 German T2DM patients. J Diabetes Complications 2015; 29: 1015-1023.
17. Nguyen AQ, Foy MP, Sood A, Gonzalez MH. Preoperative risk factors for postoperative urinary tract infection after primary total hip and knee arthroplasties. J Arthroplasty 2021; 36: 734-738.

18. Geerlings SE, Stolk RP, Camps MJL, et al. Risk factors for symptomatic urinary tract infectionin women with diabetes. Diabetes Care 2000; 23: 1737-1741.

19. Kelestimur F, Pasaoglu H, Basar E, et al. Asymptomatic bacteriuria in patients with diabetes mellitus. Mikrobiol Bull 1990; 24: 126-132.

20. Laway BA, Nabi T, Bhat MH, Fomda BA. Prevalence, clinical profile and follow up of asymptomatic bacteriuria in patients with type 2 diabetesprospective case control study in Srinagar, India. Diabetes \& Metabolic Syndrome. Clin Res Rev 2021; 15: 455-459.

21. Meiland R, Geerlings SE, Stolk RP, et al. Asymptomatic bacteriuria in women with diabetes mellitus: effect on renal function after 6 years of follow-up. Arch Intern Med 2006; 166: 2222-2227.

22. Heidemann J, Schmitz B, Kostev K. Association between antiseizure medication use and risk of urinary tract infection: a case control study. Epilepsy Behav 2021; 115: 107502.

23. Mitchell BG, Prael G, Curryer C. The frequency of urinary tract infections and the value of antiseptics in community-dwelling people who undertake intermittent urinary catheterization: a systematic review. Am J Infect Control 2021; S0196-6553: 00022-00025

24. Lusardi G, Lipp A, Shaw C. Antibiotic prophylaxis for short-term catheter bladder drainage in adults. Cochrane Database Syst Rev 2013; 2013: CD005428

25. Kashif U, Riaz N, Ramasubramanian SP, Iles D. Urogynaecological complications in pregnancy. Obstet Ginecol Reprod Med 2021; 31: $42-47$.

26. Baraka MA, Hussain Al, Lehaibi LH, Al-Suwaidan HN, et al. Patterns of infections and antimicrobial drugs' prescribing among pregnant women in Saudi Arabia: a cross sectional study. J Pharm Policy Pract 2021; 14: 9.

27. Sheiner E, Mazor-Drey E, Levy A. Asymptomatic bacteriuria during pregnancy. J Matern Fetal Neonatal Med 2009; 22: 423-427.

28. Mazor-Dray E, Levy A, Schlaeffer F, Sheiner E. Maternal urinary tract infection: is it independently associated with adverse pregnancy outcome? J Matern Fetal Neonatal Med 2009; 22: 124-128.

29. Emamghorashi F, Mahmoodi N, Tagarod Z, Heydari ST. Maternal urinary tract infection as a risk factor for neonatal urinary tract infection. IJKD 2012; 6:178-180.

30. Bauer HW, Alloussi S, Egger G. A long-term,multicenter, double-blind study of an escherichia coli extract (OM-89) in female patients with recurrent urinarytract infections. Eur Urol 2005; 47: 542-548.

31. Malmartel A, Ghasarossian Ch. Bacterial resistance in urinary tract infections in patients with diabetes matched with patients without diabetes. J Diabetes Complications 2016; 30: 705-709.

32. Ali SB, Perdawood D, Abdulrahman RM, et al. Vitamin D deficiency as a risk factor for urinary tract infection in women at reproductive age. Saudi J Biol Sci 2020; 27: 2942-2947.

33. Société de Pathologie Infectieuse de Langue Française. Diagnostic etantibiothér-apie disinfection surinaires bactériennes communautairesdel'adulte 2014.

34. Wang T, Wu G, Wang J, et al. Comparison of single-dose fosfomycin tromethamine and other antibiotics for lower uncomplicated urinary tract infection in women and asymptomatic bacteriuria in pregnant women: a systematic review and meta-analysis. Inter J Antimicrob Agents 2020; 56: 106018.

35. Lenger SM, Bradley MS, Thomas DA, et al. D-mannose vs. other agents for recurrent urinary tract infection prevention in adult women: a systematic review and meta-analysis. Am J Obstet Ginecol 2020; 223: 1-13.

36. Wade D, Cooper J, Derry F, Taylor J. Uro-Vaxom ${ }^{\circledR}$ versus placebo for the prevention of recurrent symptomatic urinary tract infections in participants with chronic neurogenic bladder dysfunction: a randomised controlled feasibility study. Trials 2019; 20: 223

37. Han L-Y, Lee Y-S. Risk factor affecting recurrence of cystitis after Urovaxom treatment for female patients with recurrent cystitis. Neurourol Urodynamics 2017; 36: S104.

38. Popa G, Lauber KD, Rothe H, Rugendorff E. Rezidivierende harnwegsinfektionen in der postmenopause. wirksamkeit einer oralen immuntherapie mit E. coli-fraktionen. Muenchn Med Wschr 1996; 138:713-716.

39. Recommendations of the expert team on the treatment and prevention of urinary tract infections with the immunostimulator Uro-Vaxom (OM-89). 
40. Toh SL, Boswell-Ruys CL, Lee BSB, et al. Probiotics for preventing urinary tract infection in people with neuropathic bladder. Cochrane Database Syst Rev 2017; 9: CD010723.

41. Gupta K, Chou MY, Howell A, et al. Cranberry products inhibit adherence of $p$-fimbriated Escherichie coli to primary cultured bladder and vaginal epithelium cells. J Urol 2007; 177: 2357-2360.

42. Lavigne JP, Bourg G, Combescure B, et al. In vitro and in vivo evidence of dose dependent decrease of uropathogenic Escherichia coli virulence after consumption of commercial Vaccinium macrocarpon (cranberry) capsules. Clin Microbiol Infect 2008; 14: 350-355.

43. Stapleton AE, Dziura J, Hooton TM, et al. Recurrent urinary tract infection and urinary Escherichia coli in women ingestingCranberry juicedaily: a randomized controlled trial. Mayo Clin Proc 2012; 87: 143-150.

44. Jepson RG, Williams G, Craig JC. Cranberries for preventing urinary tract infections. Cochrane Database Syst Rev 2012; 10: CD001321.

45. Albert X, Huertas I, Pereiro II, Sanfelix J, Gosalbes V, Perrota C. Antibiotics for preventing recurrent urinary tract infection in non-pregnant women. Cochrane Database Syst Rev 2004; 3: Cd001209.

46. Ahmed H, Farewell D, Jones HM, et al. Antibiotic prophylaxis and clinical outcomes among older adults with recurrent urinary tract infection cohort study. Age Ageing 2019; 48: 228-234.

47. NICE guideline. Urinary tract infection (lower): antimicrobial prescribing. www.nice.org.uk/guidance/ng109.

48. Hryniewicz W, Holecki M. Rekomendacje diagnostyki, terapii i profilaktyki zakażeń układu moczowego u dorosłych. Wydawnictwo sfinansowane ze środków będących w dyspozycji Ministra Zdrowia w ramach programu zdrowotnego „Narodowy Program Ochrony Antybiotyków na lata 2011-2015". 